\title{
HOW LONG DO HOUSING CYCLES LAST? A DURATION ANALYSIS FOR EMERGING ECONOMIES
}

\author{
Maryam Akbari Nasiri \\ Victorian Department of Treasury and Finance, Melbourne, Australia. Email: akbari.nasiri@gmail.com
}

\begin{abstract}
In this paper, I empirically study the amplitudes and durations of housing cycles in selected emerging countries. Using the Harding and Pagan (2002) approach, I identify peaks and troughs of house prices for 10 countries. I find that, on average, housing expansions last longer and have greater amplitudes than housing contractions. I, then, estimate a discrete time survival model of housing expansions and contractions. I show that both contractions and expansions have positive duration dependence. I find that inflation and economic growth are useful predictors for the end of periods of expansions and contractions.
\end{abstract}

Keywords: Housing cycles; Duration; Amplitude; Economic growth.

JEL Classifications: R30; F44.

\author{
Article history: \\ Received : March 17, 2019 \\ Revised : October 17, 2019 \\ Accepted : June 16, 2020 \\ Available online : June 30, 2020 \\ https://doi.org/10.21098/bemp.v23i2.1295
}




\section{INTRODUCTION}

Understanding movements in house prices as a non-tradable durable good is fundamental for economic and financial development given that the housing sector is often at the centre of a financial crisis (Kartashova and Tomlin, 2017; Iyke, 2018). The boom and bust cycles in the housing market have consequences for the rest of the economy, including consumption (see, e.g., Campbell and Cocco, 2007; Attanasio et al., 2009; Bostic et al., 2009 and Kartashova and Tomlin, 2017), employment (see, e.g., Adelino, et al., 2015; Byun, 2010), wages (see, e.g., Pischke, 2018), and inflation (see, Demary, 2010).

Housing constitutes a considerable share of household assets in many countries. The OECD's household debt indicator shows that the share of household debt of net disposable income for developed countries is more than $100 \%$ and for developing countries, this ratio is around $50 \% .{ }^{1}$ Movements in housing prices can affect households' wealth and borrowing and spending decisions. Shifts in housing prices have large flow-on effects on a nation's overall consumption, investment, and saving decisions (see, e.g., Bahaj et al. 2019; Chaney et al. 2012; Mian and Sufi, 2011). This means that being able to accurately forecast the magnitude and duration of house price movements is crucial to social planners, especially given the recent rise in global uncertainty following the coronavirus outbreak. ${ }^{2}$

Apparently, the housing system in less developed countries is different from developed countries because of various underlying factors. The main component of a well-functioning housing system is housing finance (see, for example, Warnock and Warnock, 2008; and Zhu, 2006). Several studies compare the housing finance structure across and within developed and emerging countries. Davies, Gyntelberg, and Chan (2007), for example, examine the role of government-supported housing finance agencies in Asia and find that the level of government support provided to housing finance agencies differs across countries, but is generally small relative to the economy. This implies that households in emerging countries need to selffinance their home purchase and large proportion of household saving does not pass through financial institutions. Warnock and Warnock (2008) investigate housing finance in developed and emerging countries. They find that countries with stronger legal rights for borrowers and lenders, deeper credit information systems, and a more stable macroeconomic environment have deeper housing finance systems. These factors determine the variation in housing finance between developed and developing economies.

Studying the housing market in emerging countries is important given that over the last two decades both equity and housing price booms were more pronounced in emerging countries than in developed countries (Posedel and Vizek, 2009, 2011; Syriopoulos, 2006). This study empirically investigates the housing market in emerging economies. Specifically, I examine house price cycles across a panel of 10 countries, namely South Africa, Mainland China, Greece, Hungary, Indonesia,

1 The OECD's household debt data is available at https://doi.org/10.1787/f03b6469-en and is accessed on 17 March 2020.

2 Several studies highlight the rise of global uncertainty following the coronavirus outbreak and the need to formulate appropriate policies to mitigate the consequences of this disruption (see, e.g., Devpura and Narayan, 2020; Haroon and Rizvi, 2020; Iyke, 2020a,b; Mishra et al., 2020; Narayan, 2020; Phan and Narayan, 2020; Prabheesh et al., 2020; Vidya and Prabheesh, 2020). 
South Korea, Malaysia, Romania, Thailand and Taiwan. I use data for the 1995 to 2018 period. By adopting a pattern-recognition method developed by Bry and Boschan (1971) (henceforth, BB algorithm), I identify turning points in house prices and find that, consistent with Bracke (2013), upturns, on average, last longer and are greater in magnitude than downturns.

I also test for duration dependence in house price expansions and contractions. I do so by estimating a discrete time survival model with a logit specification. I find that house price contractions and expansions in emerging markets have positive duration dependence since their exit probabilities increase with duration. If there is duration dependence in housing cycles then their turning points can be to some extent predicted by the duration of the phase. Thus, duration could prove to be a useful indicator for policy makers. Understanding this behaviour is, thus, of key interest to central banks charged with maintaining price and financial stability.

I further explore the factors that can serve as early warning signals of housing market booms and busts in emerging economies. Our results show that expansionary and contractionary phases are not completely explained using the standard house price determinants but exhibit duration dependence. These findings are interesting to policy makers since duration could be a useful indicator in predicting the length of housing market cycles.

While empirical analysis on developed countries shows that house price dynamics are mostly driven by income, demographics, economic condition, interest rate, and credit to private sector (see, e.g., Angello and Schuknecht, 2011; Bracke, 2013), I find that inflation can determine the duration of downturns, and economic growth is the main predictor of upturn duration in the housing markets of our selected emerging economies.

It should be noted that while there are a few studies on housing cycle durations in developed countries (see, e.g., Cunningham and Kolet 2011; Bracke, 2013), there is nothing on about housing cycle durations in less developed economies. I contribute to this literature by examining whether duration dependence exists in housing cycles in emerging economies. I provide a detailed analysis of the evolution of housing cycles in emerging countries. Then, through a survival model, I test whether contractions and expansions in emerging countries are duration dependent. Finally, I establish what macro variables are useful for predicting turning points in emerging countries' housing cycles.

\section{LITERATURE REVIEW}

The study touches on two strands of literature. First, this study is closely related to the literature on duration dependence in economic cycles. This literature examines whether the age of the current phase of the cycle or the duration of previous cycles affect the probability that the phase will terminate in the next period. The survival model (typically referred to as the hazard or duration model) is commonly used in predicting the length of time that an individual remains in his/her current state. There is a positive duration dependence if duration in a given phase increases the likelihood of termination. On the contrary, there is negative duration dependence if duration reduces the termination probability. 
While most studies focus on stock market cycles (see, e.g., Lunde and Allan, 2004; Harman and Zuehlke, 2007) and business cycles (See, e.g., Lam, 2004; Ohn, Taylor and Pagan, 2004), there is a lack of focus on housing duration. The few existing studies mainly focus on advanced economies. Cunningham and Kolet (2011), for example, focus on duration dependence in housing cycles for the US and Canada. They find a positive duration dependence for the US housing market expansions, while Canadian house price cycles do not exhibit duration dependence. Similarly, Bracke (2013) focuses on a sample of OECD countries and shows that house price upturns and downturns are duration dependent and are more likely to end as they get longer. Ciarlone (2015) is one of the few studies focusing on the characteristic of house price dynamics in emerging economies. He links housing valuations to a set of conventional fundamental determinants relative to both the supply and the demand side of the market, institutional factors, and other asset prices. He finds that housing markets have rarely displayed signs of overvaluation (undervaluation) and house prices seem disconnected from the fundamentalbased 'equilibrium' levels. While a few studies examined the duration dependence of housing cycles in developed countries, no study examined the issue in the context of emerging economies. This study extends the literature by studying the characteristics of housing market cycles and duration dependence in emerging countries.

Second, our study also belongs to the strand of literature that focuses on identifying the macroeconomic determinants of house prices. Agnello and Schuknecht (2011) used a probit model to identify the factors correlated with the occurrence of boom and bust phases and find that credit and financial conditions affect the probability of housing booms and busts. Bracke (2013) also explore the role of fundamentals in housing cycles for 19 OECD countries. He found that the interest rate, working age population, inflation, and economic activity impact the probability of housing cycle durations. I extend this literature to see whether macroeconomic variables in emerging countries can be used as the determinants of housing cycles.

\section{DATA AND METHODOLOGY}

Residential property prices have some limitation that make data collection difficult. While some time series are constructed based on the hedonic pricing method, others are based on repeat sales. Besides, in some cases, countries publish house prices in national currency per-square metre. Another issue is calculating the house price index based on different base years. Aware of these kinds of issues, I obtain data for house price index from DataStream. I also extract the variables used as potential determinants of equilibrium house prices from DataStream, the OECD's website, and the Federal Reserve Bank of St. Louis (FRED). There were 16 emerging countries that have house price indices data, but six countries have numerous missing data for the macroeconomic variables. For this reason, those countries were excluded from the sample. Ultimately, I put together quarterly data for 10 emerging economies - six from Asia (i.e. China, Korea, Malaysia, Taiwan, Indonesia, and Thailand), three from Central and Eastern Europe (i.e. Romania, Hungary, Greece), and one from Africa (South Africa). The sample period is from March 1995 to Dec 2018. 
The first debated issue in the duration literature is how the beginning and ending of housing price cycles should be identified. While Bordo and Jeanne (2002) and Borio and Lowe (2002) detect a boom or bust in asset price series when the 3-year average of the growth rate falls outside a confidence interval, in housing market context, Ceron and Suarez (2006) used a Markov-switching model to define the start and end of housing cycles. I do not use the Markov-switching model as it is only reliable when probabilities are known. Instead, I closely follow Harding and Pagan (2002) and adopt the BB algorithm to detect turning points in our quarterly house price data.

The dating procedure consists of finding a series of local maxima and minima that segments the time series into expansionary and contractionary phases. The algorithm requires implementing the following three steps on a quarterly series $y_{t}$. First, I identify points that are higher or lower than a window of surrounding observations. Using a window of $k$ quarters on either side, a local maximum, $y_{t}^{*}$, is defined as an observation of the series, such that $y_{t-k}, \ldots, y_{t-1}>y_{t}^{-}<y_{t+1}, \ldots, y_{t+k}$. A local minimum must satisfy: $y_{t-k}, \ldots y_{t-1}<y_{t}^{+}>y_{t+1}, \ldots, y_{t+k}$ by symmetry. The second step is the censoring rule. For this purpose, the distance between two turning points must be at least $q$ quarters, where $q$ is chosen to retrieve only significant series movements and avoid series' noise. The final step is the so-called alternating rule. Based on this rule, a local maximum must be followed by a local minimum and vice versa. If there are two consecutive maxima (minima), the highest (lowest) $y_{t}$ is chosen.

The algorithm would then label peaks as " 1 ", troughs as "- 1 " and all other months as 0 . An additional decision to be made is regarding the rolling window requirement $(k)$ and minimum phase duration $(q) .^{3}$ In our analysis, I follow Bry and Boschan (1971) and set $k=3$ quarters as the window over which the local minima and maxima are computed, and $q=2$ quarters as the minimum phase length and $c=5$ as the minimum length of the cycle.

Later in the analysis, I use survival analysis to test for duration dependence and explore the determinants of housing cycles. In survival analysis, two related probability functions are estimated, namely the hazard function and the survivor function. The hazard function is a conditional density function describing the probability of country $i$ leaving the current state at time $t$, conditional on the current state having survived until $t-1$. The survivor function is simply one minus the hazard function, and it describes the conditional probability of the current state continuing for country $i$. I estimate discrete (rather than continuous) time survival models for housing expansion and contraction phases. For this approach, I use a standard probit model and specify a binary dependent variable as a function of our measures of duration in the current phase and the fundamental factors affecting housing cycle durations. I provide detailed explanations of the model in the following sections.

3 I used the sbbq command in Stata for this algorithm. 


\section{CHARACTERISTICS OF UPTURNS AND DOWNTURNS}

The two most important characteristics of cyclical phases are amplitude and duration. Duration for downturn cycles is defined as the number of quarters between a peak and a trough, while for upturn cycles, duration is the number of quarters between a trough and peak. Amplitudes measure the percentage increase or decrease of house prices during an upturn or a downturn. Table 1 displays the peaks and troughs across selected emerging countries and Tables 2 and 3 display all the durations and amplitudes. Table 2 shows that the duration of housing market upturns in our sample ranges from 10 to 138 quarters. Moreover, it indicates that upturn phases, as compared to downturns, are on average longer (i.e. 56.9 quarters vs 16.9 quarters) and greater in magnitude (i.e. $70.8 \%$ vs $6.9 \%$ ). These characteristics are consistent with studies on other OECD countries (see Bracke, 2013).

Table 4 reports the descriptive statistics (mean, standard deviation, minimum, and maximum) for durations and amplitudes for the selected emerging countries, distinguishing between expansionary and contractionary phases.

Overall, the average expansion in these selected emerging economies features an increase in house prices of $113 \%$ in upturns, while the average price change in downturns is $-15.6 \%$. Based on the average 18.9 quarters as the duration of upturns and 10.6 quarters for downturns, this implies a quarterly price growth rate of $5.99 \%$ and $-1.47 \%$ for upturns and downturns, respectively.

Characteristics of house price cycles within countries show that Thailand experienced the longest upturn (66 quarters), followed by Taiwan (63 quarters). In terms of downturn, Malaysia has the most extended downturn (30 quarters), followed by Romania (22 quarters). China, Malaysia, and South Africa are countries that have nearly consistent upward trend, experiencing only one downturn. Greece and Romania have the most volatile housing markets.

In terms of the amplitude, South Korea has the highest price growth in upturns (348.6\%) followed by Taiwan (244\%). The average price change in the selected emerging countries' downturns is $-15.6 \%$, while Malaysia has the sharpest price drop $(-67.2 \%)$ and Thailand has the lowest price change $(-2.3 \%)$, among these countries.

Figure 1 plots peaks and troughs against the corresponding housing price indices. The graphs show that house prices in these emerging economies grow fast and are less volatile, although most of the countries experienced downturns during the global financial crisis. The patterns of housing cycles in Asian countries are comparable. Unreported correlation results indicate some degree of synchronization in house price movements across these countries.

I find some evidence of co-movements in house prices, especially across the Asian countries. Among the European countries, while Greece is highly correlated with Romania, it is uncorrelated with Hungary. South Korea seems less synchronized with other countries in our sample. This characteristic motivates us to use the country-fixed effects in our empirical analysis. 


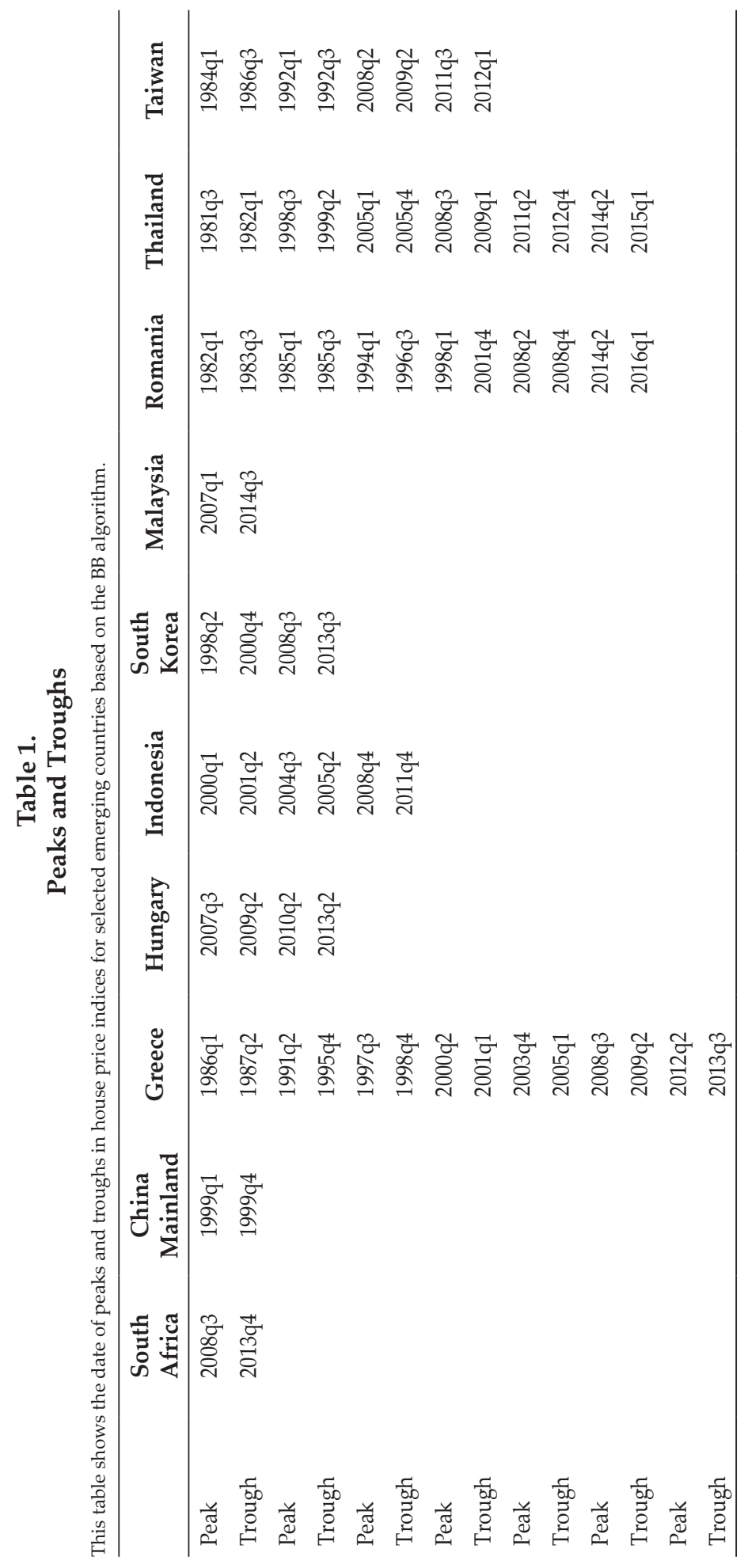




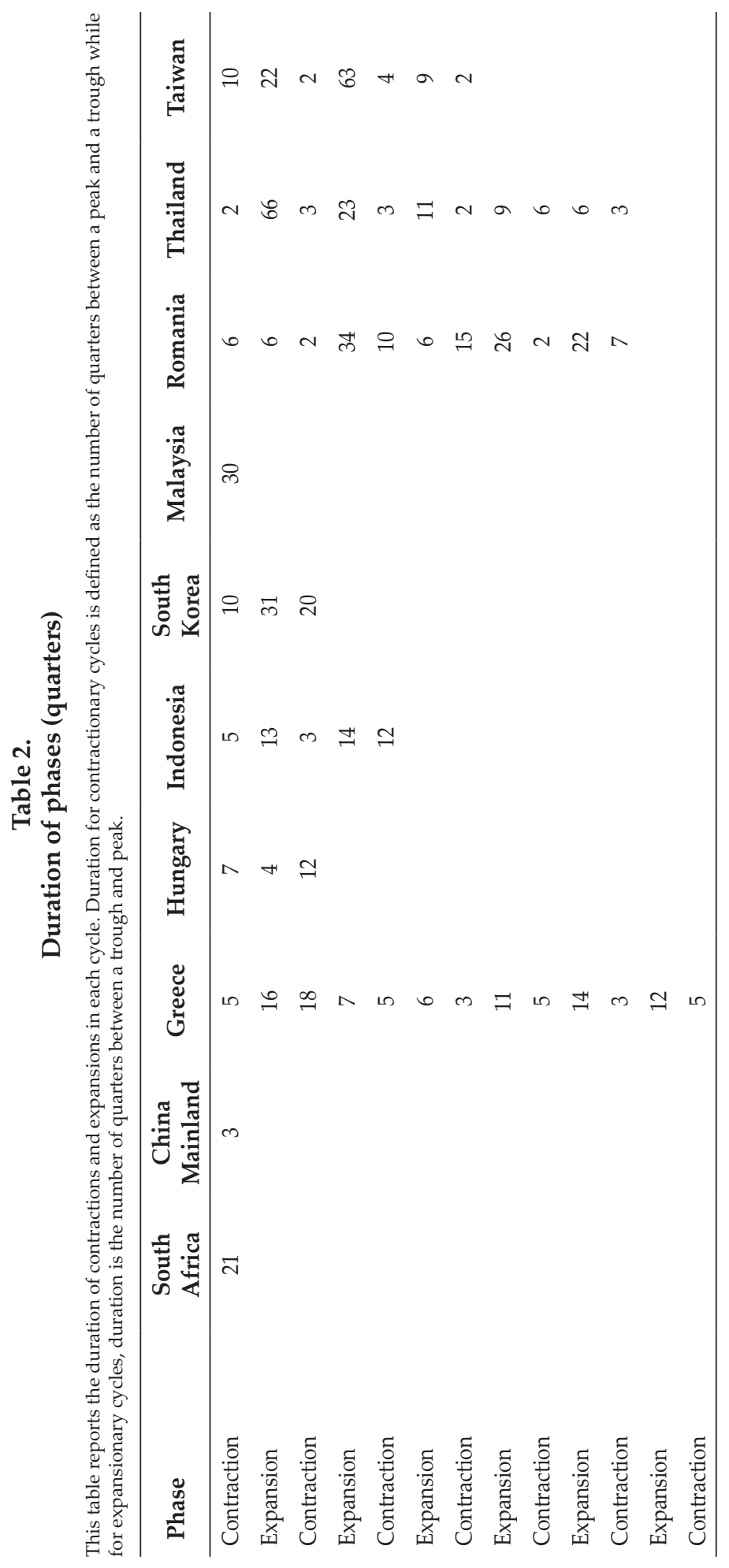




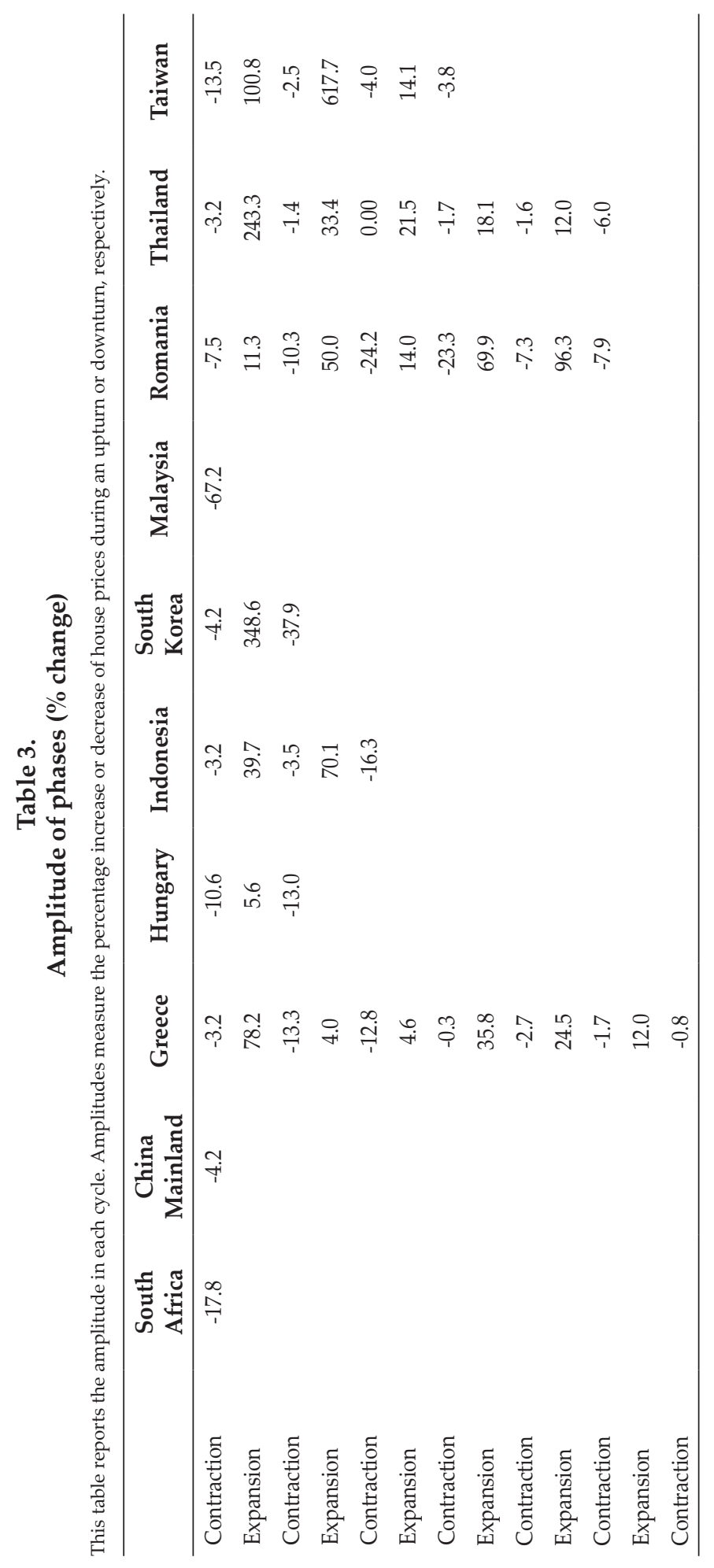




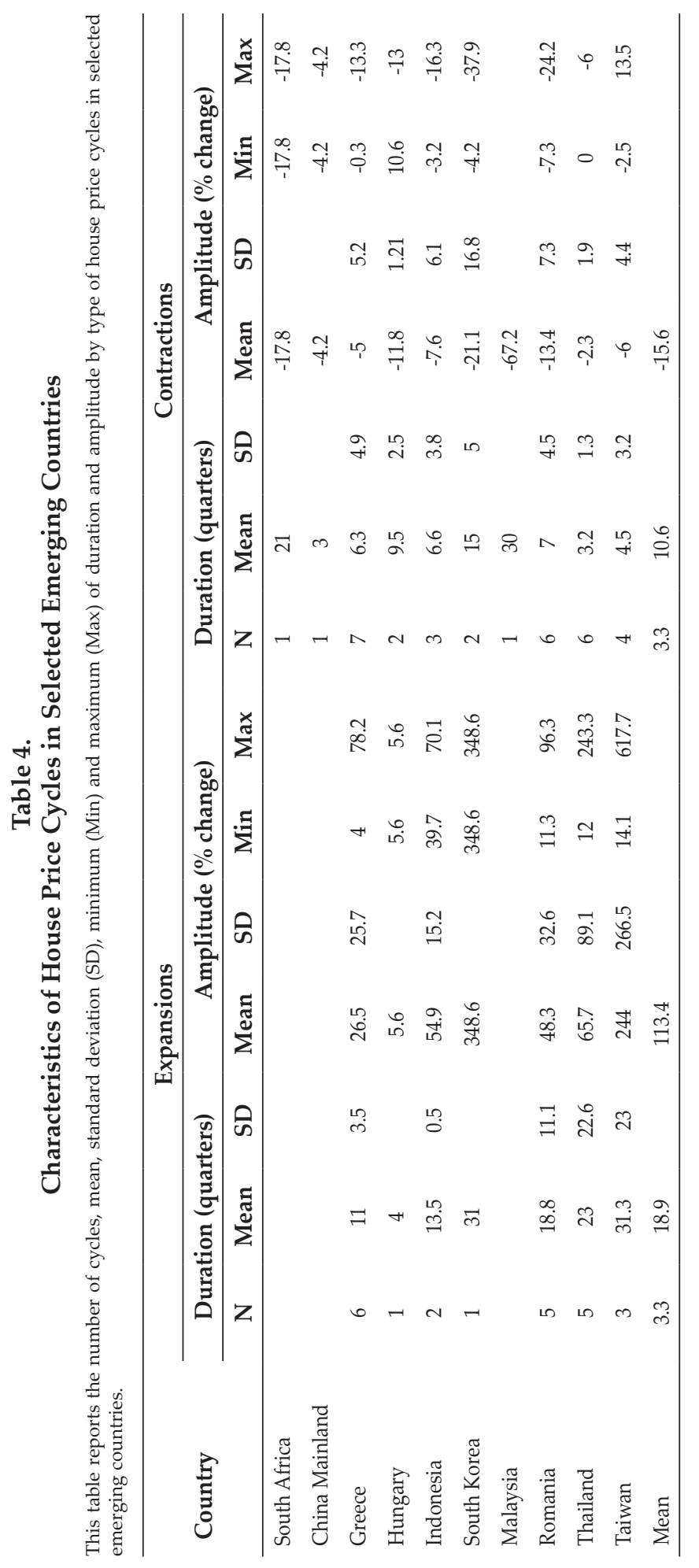


Figure 1.

\section{House Price Index}

These figures show house price indices and turning points in selected emerging countries. Grey lines indicate downturns and black lines indicate upturns.
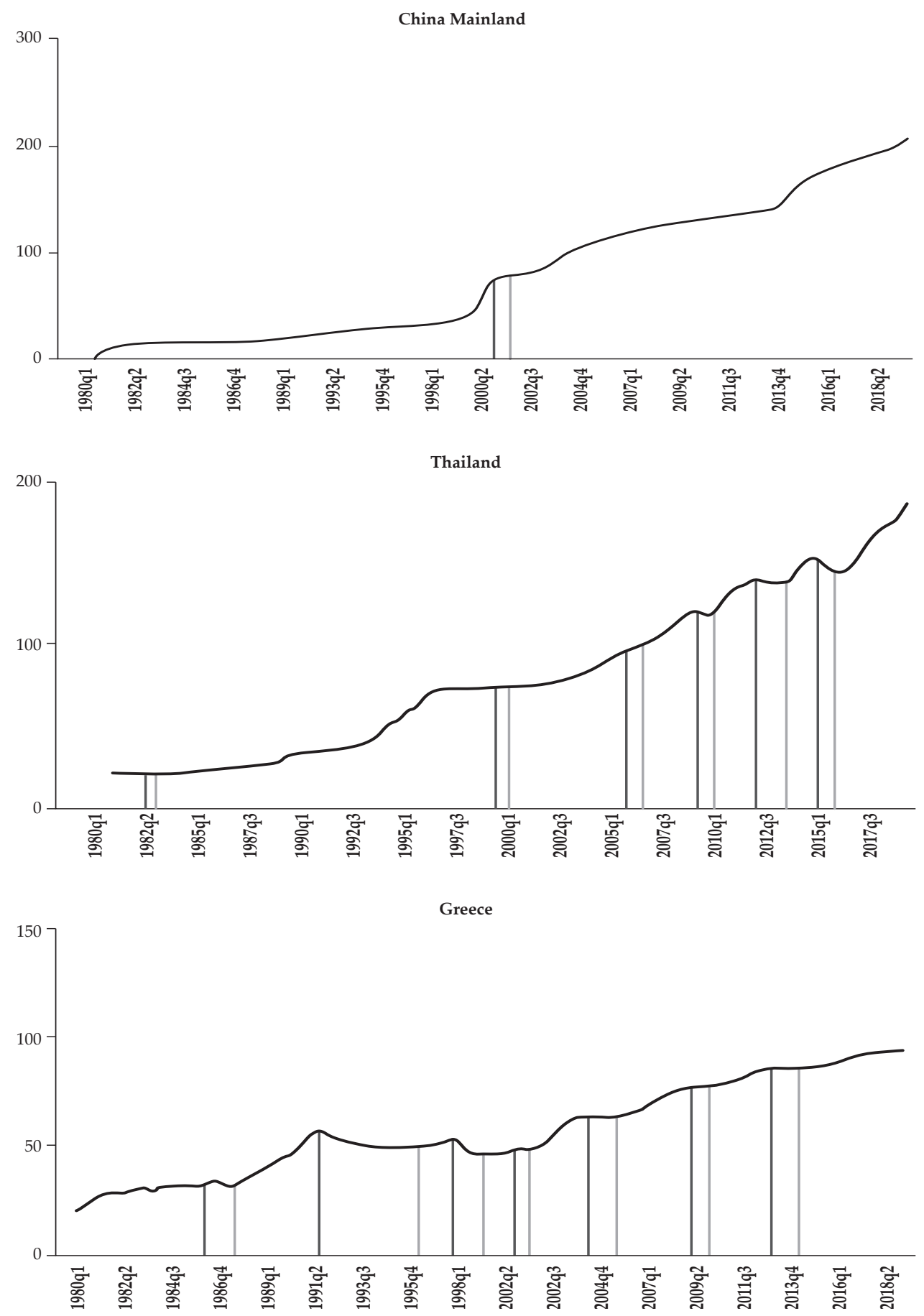
Figure 1.

House Price Index (Continued)

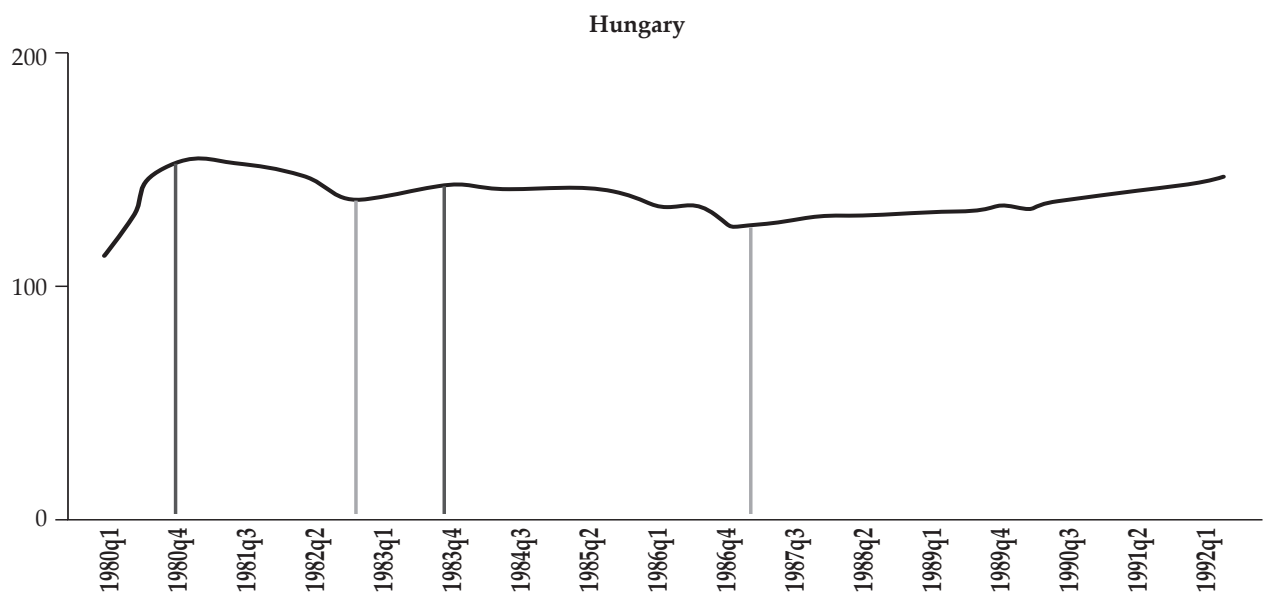

South Africa
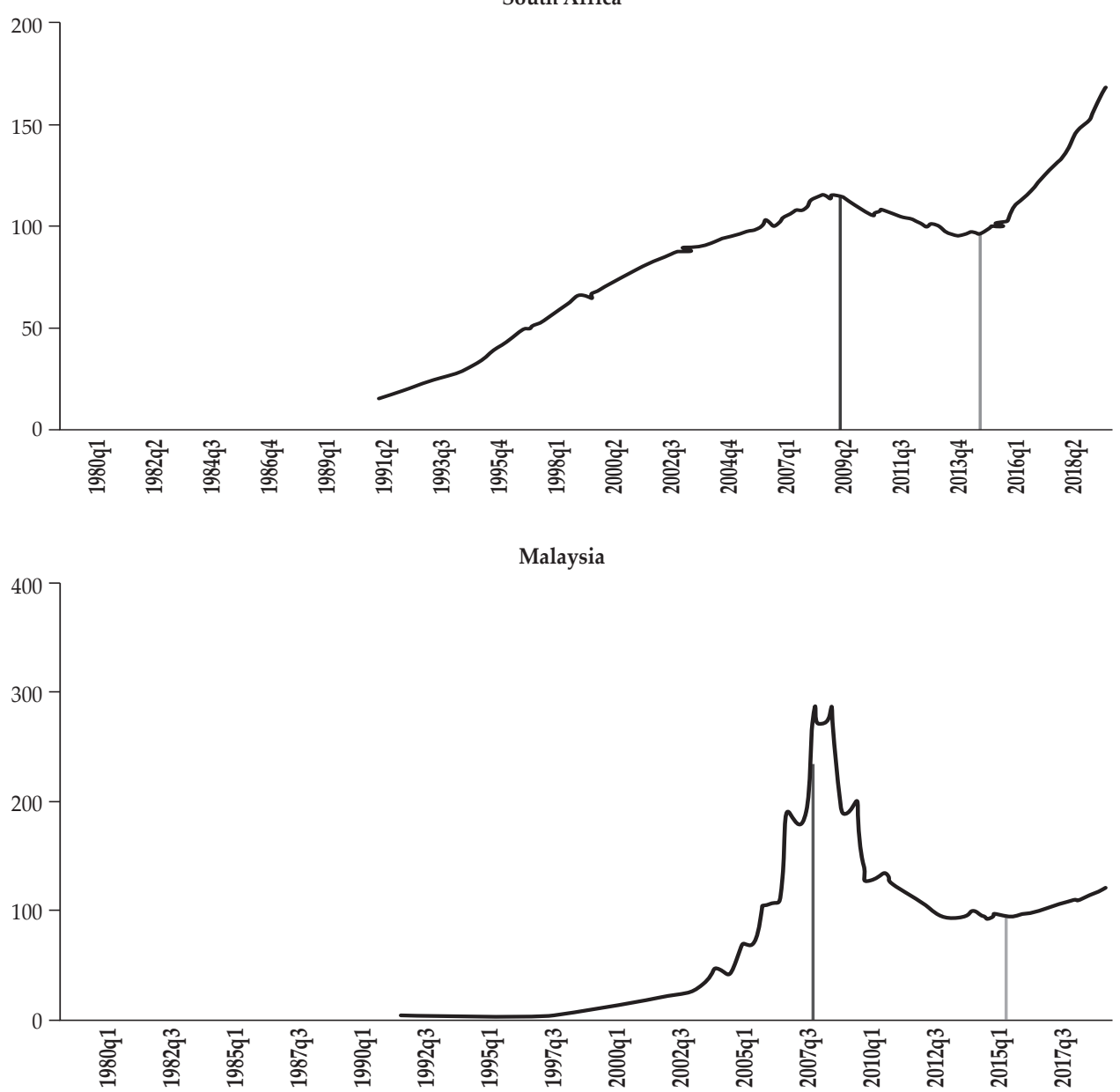
Figure 1.

House Price Index (Continued)

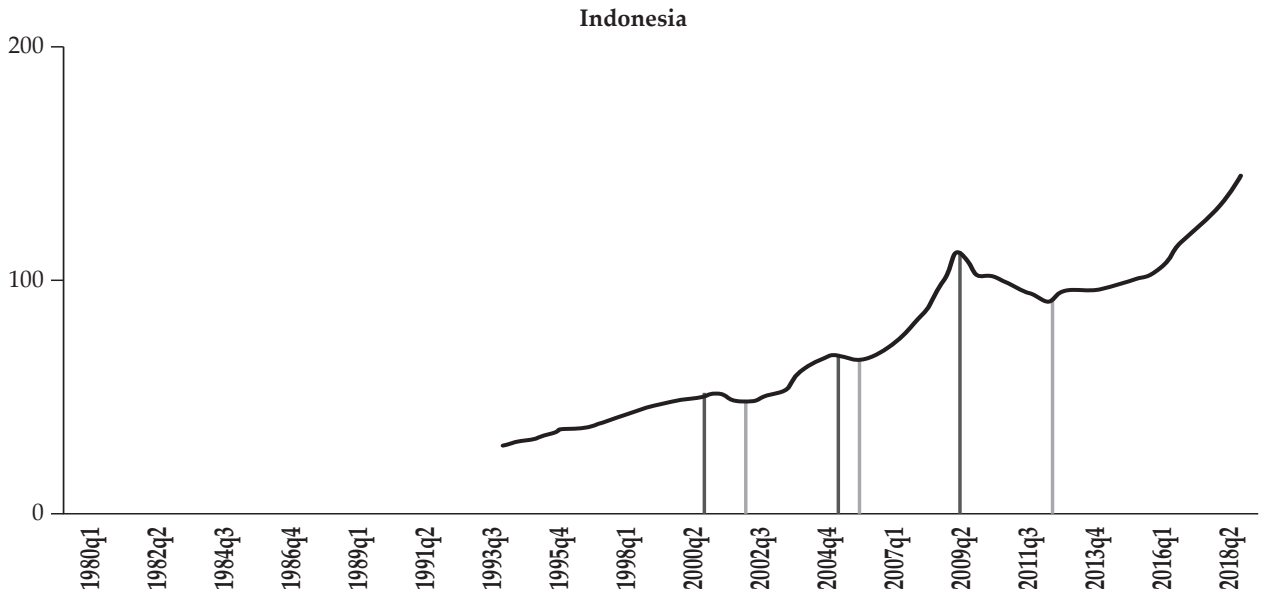

South Korea

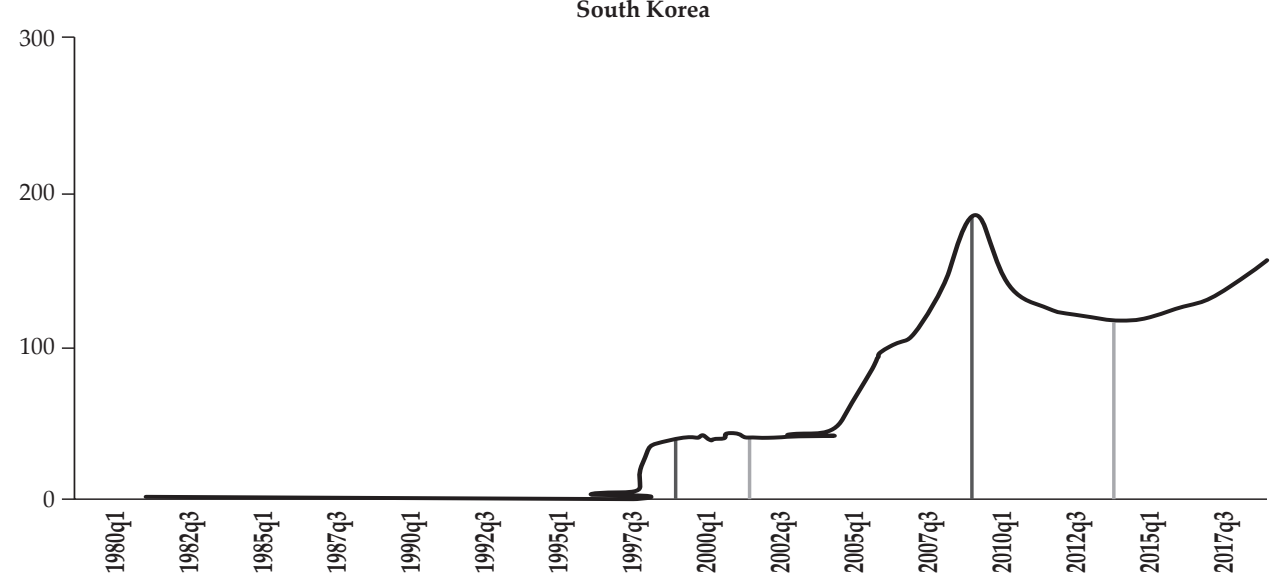

Romania

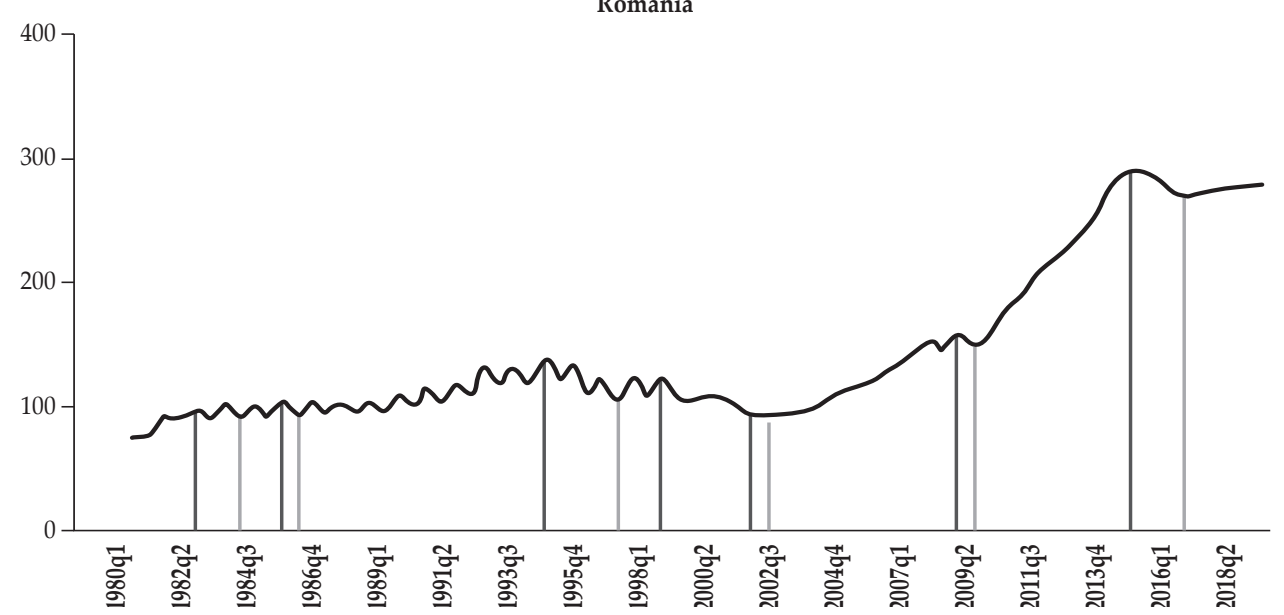


Figure 1.

House Price Index (Continued)

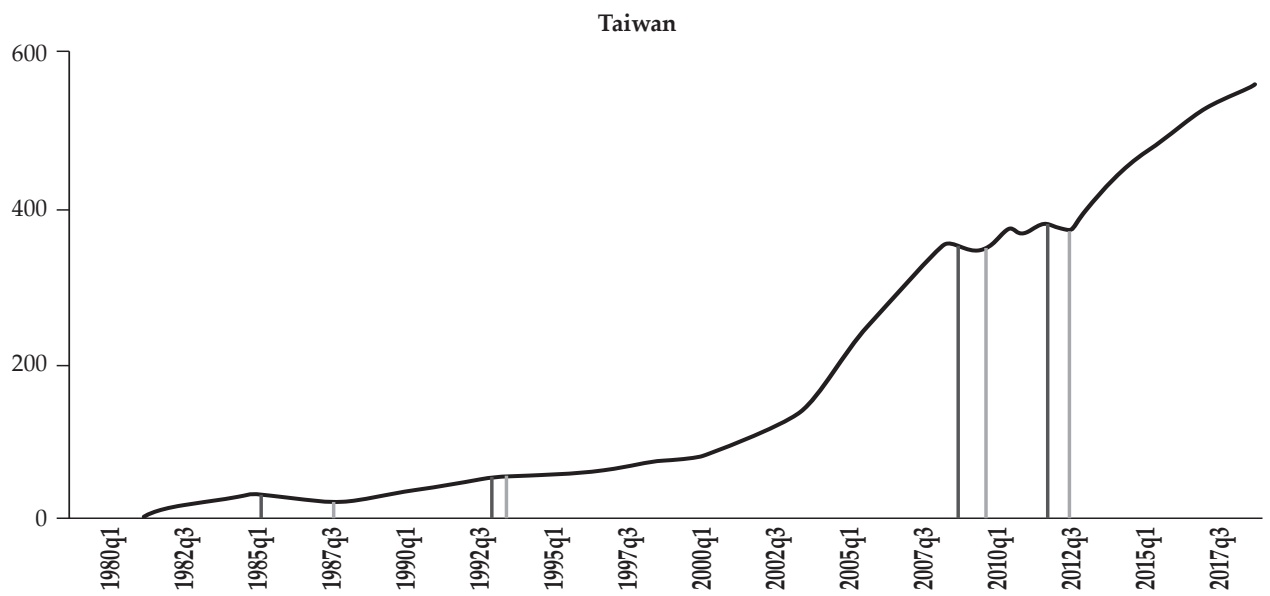

\section{DURATION DEPENDENT TEST}

In the previous section, I provide results for the average duration of the cycle phases without describing the whole distribution of realized upturn or downturn lengths. The duration of a given upturn or downturn can be useful in predicting the probability of ending that cycle. The average duration of phases is not informative for this purpose and neglects useful information.

Basically, I are interested in knowing whether a long expansion is likely to terminate than a shorter one. If there is duration dependence, then the mean reversion pattern and turning points in house prices cycles could be predicted by the duration of the phase.

To check whether an emerging country's housing cycles exhibit duration dependence, I follow the method by Ohn et al. (2004) and Bracke (2013). To test for duration dependence in downturns (upturns), I generate a binary variable $S_{i, t}$ that takes value 1 if country $i$ in quarter $t$ is in an upturn (downturn) and 0 otherwise. Then, I keep all observations that belong to downturns (upturns) plus the first observation that signifies the beginning of every upturn (downturn) after a sequence of $S_{i, t}=0$. The equation that I estimate is:

$$
\operatorname{Pr}\left(S_{i t}=y_{1} \mid S_{i t-1}=y_{2}\right)=\Lambda\left(\alpha_{s}+\beta d_{i, t-1}+\gamma_{t}\right)
$$

where $d_{i, t}$ is the ongoing duration of the current phase at time $t,\left(y_{1}, y_{2}\right)=(0,1)$, $y_{t}$ is country fixed-effect and $\wedge()$ is the logistic function. In this logistic model, the probability of an event is modelled by Equation (2). I use a logit regression as our baseline specification.

$$
p=e^{X \beta}\left(1+e^{X \beta}\right)^{-1}
$$


Column 1 in Table 5 reports the results of the duration dependence test in upturns and downturns. The results indicate a significant and positive effect of duration on the probability of ending the downturns and upturns. A statistically significant nonzero coefficient $(\beta)$ denotes that downturns and upturns in selected emerging countries are duration dependent. A statistically significant positive coefficient implies that the longer the duration already spent in the current phase, the more likely it is to terminate. In other words, the longer the expansion/ contraction has already lasted, the less likely it is surviving another year. This implies that housing market expansions/contractions have positive duration dependence. This may not be surprising for downturns, since policy makers are strategizing to end recession phases. For upturns, policy makers could potentially look to the duration of an expansion cycle to help estimate when an upturn is likely to terminate and are cautious about the consequence of that for the economy.

The marginal effects of variables in logistic regression is calculated using Equation (3). I report the marginal effects of the variables in Table 5. The marginal effects of the duration of a downturn on the probability of ending that cycle is larger and more significant relative to an upturn.

$$
m_{j}=\frac{\partial p}{\partial X_{J}}=\beta p(1-p)
$$

Table 5.

\section{Duration Dependence Test}

This table reports the result of duration dependence test. Panel A has parameter estimates while Panel B presents the marginal effect of each variable. $d_{c t-1}$ is the duration of the current cycle and $l_{c t-1}$ is the duration of the previous cycle. $\mathrm{N}$ is the number of observations. Finally, ${ }^{* * *}, * *$, and * denote results are significant at the $1 \%, 5 \%$ and $10 \%$, respectively.

\begin{tabular}{|c|c|c|c|c|}
\hline \multicolumn{5}{|c|}{ Panel A: } \\
\hline \multirow[t]{2}{*}{ Parameter estimate } & \multicolumn{2}{|c|}{ Contractions } & \multicolumn{2}{|c|}{ Expansions } \\
\hline & (1) & (2) & (3) & (4) \\
\hline \multirow{2}{*}{$d_{c, t-1}$} & $0.292^{* * *}$ & $0.293^{* * *}$ & $0.059^{* *}$ & $0.066^{* *}$ \\
\hline & $(3.51)$ & $(3.52)$ & $(2.14)$ & $(2.34)$ \\
\hline \multirow[t]{2}{*}{$l_{c, t-1}$} & & 0.012 & & 0.003 \\
\hline & & $(0.40)$ & & $(0.06)$ \\
\hline Pseudo $R^{2}$ & 0.18 & 0.19 & 0.05 & 0.06 \\
\hline Country FE & $\sqrt{ }$ & $\sqrt{ }$ & $\sqrt{ }$ & $\sqrt{ }$ \\
\hline $\mathrm{N}$ & 177 & 177 & 380 & 380 \\
\hline \multicolumn{5}{|c|}{ Panel B: } \\
\hline Marginal effect & \multicolumn{2}{|c|}{ Contractions } & \multicolumn{2}{|c|}{ Expansions } \\
\hline \multirow[t]{2}{*}{$d_{c, t-1}$} & 0.025 & 0.025 & 0.0002 & $0.003^{* *}$ \\
\hline & $(3.65)$ & (3.66) & $(0.23)$ & $(2.20)$ \\
\hline \multirow[t]{2}{*}{$l_{c, t-1}$} & & 0.001 & & 0.0001 \\
\hline & & $(0.40)$ & & $(0.06)$ \\
\hline
\end{tabular}


Some studies, such as Claessens et al. (2011) and Agenllo and Schuknecht (2011), discuss that the duration of downturns should depend on the duration of previous upturns. In the next step, I test this hypothesis, which is known as the "lagged duration dependence", by including the duration of the previous phase $\left(l_{c, t-1}\right)$ in the regression:

$$
\operatorname{Pr}\left(S_{i t}=y_{1} \mid S_{i t-1}=y_{2}\right)=\Lambda\left(\alpha_{s}+\beta d_{i, t-1}+\delta l_{i, t-1}+\gamma_{t}\right)
$$

Column 2 in Table 5 reports these results. The results show that the coefficient on lagged duration $\left(l_{c, t-1}\right)$ is insignificant in predicting the end of upturns and downturns, which means that there is no evidence for the lagged duration dependence for housing cycles in these countries.

\section{DETERMINANTS OF BOOMS AND BUSTS IN HOUSING MARKETS}

In this section, I identify the factors than can be considered as the early warning signals of booms and busts in the housing markets of the emerging economies. Furthermore, this technique may also be a beneficial when examining which monetary policy affects the duration of housing price cycles and the timing of turning points. For this purpose, I augment the survival model in Section 4 with the following five variables commonly used as the determinants of house prices in the relevant literature: namely, interest rate, inflation, gross domestic product, employed persons, and wage (see, e.g., Angello and Schuknecht, 2011; Bracke, 2013). ${ }^{4}$ The unit root tests indicate that the growth rates of inflation, economic growth, number of employed people, income, and the first difference of the interest rate are all stationary, so I use these transformed variables in our regressions. ${ }^{5}$

Table 6.

\section{Summary Statistics for Covariates}

This table reports the details of the macroeconomic variable that I used in our model.

\begin{tabular}{|c|c|c|c|c|c|}
\hline \multirow{2}{*}{ Variables } & \multirow{2}{*}{ Definition } & \multicolumn{2}{|c|}{ Contraction } & \multicolumn{2}{|c|}{ Expansion } \\
\hline & & Mean & SD & Mean & SD \\
\hline$I R_{t}$ & Quarterly change in interest rate & -0.12 & 2.45 & -0.09 & 0.50 \\
\hline$C P I_{(i, t)}$ & $\begin{array}{l}\text { Annual growth in consumer price } \\
\text { index }\end{array}$ & 9.39 & 14.51 & 5.61 & 16.43 \\
\hline$G D P_{(i, t)}$ & $\begin{array}{c}\text { Quarterly growth in gross domestic } \\
\text { product }\end{array}$ & 0.55 & 1.36 & 0.86 & 1.08 \\
\hline$E M P_{(i, t)}$ & $\begin{array}{l}\text { Quarterly change in total number of } \\
\text { employed persons }\end{array}$ & -0.02 & 2.20 & 0.31 & 2.41 \\
\hline$W A G E_{(i, t)}$ & $\begin{array}{l}\text { Quarterly growth rate of wage } \\
\text { index }\end{array}$ & 0.40 & 2.79 & 0.65 & 2.29 \\
\hline
\end{tabular}

4 Many studies, such as Ozanne and Thibodeau (1983), Peek and Wilcox (1991), Mikhed and Zemcik (2009), Drought and Donald (2011), and Wang and Zhang (2014) find that population, especially adult population/ number of households, income, and unemployment are significant drivers of housing price growth.

5 These results are consistent with the structural break test of Narayan and Popp $(2010,2013)$. Detailed results are available upon request. 
Table 7 presents the output obtained from estimating the following equation, where $\left(y_{1}, y_{2}\right)=(0,1), \Lambda()$ is the logistic function, and $X_{i, t}$ are the macroeconomic variables:

$$
\operatorname{Pr}\left(S_{i t}=y_{1} \mid S_{i t-1}=y_{2}\right)=\Lambda\left(\alpha_{s}+\beta d_{i, t-1}+\delta l_{i, t-1}+\rho X_{i, t-1}+\gamma_{t}\right)
$$

The results indicate that economic growth is the main determinant of upturns in emerging countries, while for downturns, inflation plays a moderate role in identifying the duration of cycles. This means that an improvement in economic conditions in the emerging countries lengthens the upturn phase and inflation influences the duration of downturns. In contrast to advanced economies, whereby monetary policy indicators (i.e. interest rate or mortgage rate) appear as one of the main indicators of housing cycles, I could not find evidence for a significant role for these indicators in housing cycles for emerging markets. The most probable reason is that, as I discussed in the introduction, mortgage amounts are generally quite small in these countries and households need to self-finance their purchases. Davies et al. (2007) find that the level of government support is quite low in Hong Kong, India, Japan and Korea and negligible in Malaysia, consistent with our finding.

Table 7.

Duration Dependence With Macro Variables

This paper reports results from estimating $\operatorname{Pr}\left(S_{i t}=y_{1} \mid S_{i t-1}=y_{2}\right)=\Lambda\left(\alpha_{s}+\beta d_{i, t-1}+\gamma l_{i, t-1}+\rho X_{i, t-1}\right)$, where $\left(y_{1^{\prime}}\right.$ $\left.y_{2}\right)=(0,1), \Lambda()$ is the logistic function, and $X_{i, t-1}$ are the macro variables. Finally, ${ }^{*}, * * * * * *$ denote $1 \%, 5 \%$, and $10 \%$ significance, respectively.

\begin{tabular}{lcc}
\hline & Upturns & Downturns \\
\hline$d_{s, t-1}$ & $0.129^{*}$ & $0.223^{* * *}$ \\
& $(1.94)$ & $(2.58)$ \\
$l_{s, t-1}$ & -0.178 & -0.057 \\
& $(-1.37)$ & $(-0.61)$ \\
$I R_{t}$ & 0.821 & -0.105 \\
& $(1.16)$ & $(-0.38)$ \\
$C P I_{i, t-1}$ & 0.008 & $-0.153^{*}$ \\
& $(0.65)$ & $(-1.72)$ \\
$G D P_{i, t-1}$ & $-0.879^{* * *}$ & 0.126 \\
& $(-2.56)$ & $(0.46)$ \\
$E M P_{i, t}$ & -0.072 & 0.037 \\
$W A G E_{i,-1}$ & $(-0.42)$ & $(0.35)$ \\
Pseudo R & -0.122 & 0.051 \\
Country FE & $(-0.90)$ & $(0.36)$ \\
$\mathrm{N}$ & 0.19 & 0.18 \\
\hline
\end{tabular}


Table 7.

Duration Dependence With Macro Variables (Continued)

\begin{tabular}{lcc}
\hline & Upturns & Downturns \\
\hline$d_{s, t-1}$ & Marginal effects & \\
& 0.005 & $0.020^{* * *}$ \\
$l_{s, t-1}$ & $(1.82)$ & $(2.67)$ \\
& -0.007 & $-0.005^{* * *}$ \\
$I R_{t}$ & $(-1.32)$ & $(-0.61)$ \\
& 0.032 & $-0.009^{* * *}$ \\
$C P I_{i,-1}$ & $(1.13)$ & $(-0.36)$ \\
& 0.000 & $-0.013^{*}$ \\
$G D P_{i, t-1}$ & $(0.64)$ & $(-1.75)$ \\
\multirow{2}{*}{$E M P_{i, t}$} & $-0.033^{* *}$ & 0.011 \\
& $(-2.36)$ & $(0.46)$ \\
$W A G E_{i, t-1}$ & -0.003 & 0.003 \\
& $(-0.42)$ & $(0.35)$ \\
\end{tabular}

The results indicate that a rise in interest rate increases (decreases) the probability that upturns (downturns) terminate. A positive change in interest rate affects the household's debt financing conditions and reduces the household willingness to take debt, since it must spend a high share of its income to servicing debt. Therefore, as I expected, a higher mortgage rate decreases (increases) the probability of ending the upturns (downturns), and the marginal effect of a change in interest rate in terminating an upturn is bigger than a downturn, although it turns out to be statistically insignificant. Moreover, the results show that a growth rate in a household's income and the number of employed people reduce the likelihood of upturns ending, while it increases the probability of downturns endings. The magnitude of the marginal effect for a change in employment for upturns and downturns is equal. Moreover, economic growth measured by growth in gross domestic product turns out to be an important determinant of duration upturn with a higher marginal effect compared to downturn durations. The reverse is true for inflation. The results confirm that inflation plays a critical role in the turning point of downturns.

While the signs of the control variables are in line with our expectation, most of the considered variables are statistically insignificant. This outcome is consistent with Ciarlone (2015), who finds that the actual house prices look disconnected from fundamentals. Also, this finding is consistent with Cesa-Bianchi (2013), who finds, in contrast to advanced countries, the response of emerging countries to housing demand shock is not significantly different from zero.

The evidence of duration dependence is still strong in both downturn and upturn cycles even after including fundamental variables. As I find earlier, the 
results confirm that duration is statistically significant, which implies that cycle phases become more likely to end as they progress. This finding is important for predicting the length of market contractions and expansions. In contrast, the lagged duration dependence evidence is not valid when macroeconomic variables are modelled. The marginal effects of the duration variable on the probability of downturn terminations are larger compared to the effects on the probability of upturn terminations.

\section{CONCLUSION}

In this paper, I study the housing price cycles in 10 selected emerging countries. I mainly focus on durations and amplitudes as the main characteristics of housing cycles and test whether housing cycles in emerging economies are duration dependent. By applying the BB algorithm, I identified the peaks and troughs of housing cycles in these economies, and find that, like OECD countries, upturns in these countries have been longer than downturns. Moreover, the duration dependence test suggests that house price downturns and upturns are likely to end as they get longer.

Furthermore, I examined the determinants of housing price developments by adopting a logistic model. I find that, among the set of macroeconomic factors, economic growth plays a significant role in the occurrence of housing booms, while inflation is informative for the duration of busts. I also confirm that a growth in household's income and an increase in the number of employed people increase the probability of bust terminations and, conversely, decreases the likelihood of upturns ending. In contrast to advanced economies, it seems monetary policy does not have a fundamental role in housing cycles in emerging countries. I argue that this outcome is a result of the fact that most houses purchased is financed by the households and not the financial institutions.

\section{Akcnowledgement:}

The views expressed in this paper are those of the author and do not necessarily reflect the views of the Department of Treasury and Finance, Victoria, Australia.

\section{REFERENCES}

Adelino, M., Schoar, A., and Severino, F. (2015). House Prices, Collateral, and SelfEmployment. Journal of Financial Economics, 117, 288-306.

Agnello, L., Schuknecht, L. (2011). Booms and Downturns in Housing Markets: Determinants and Implications. Journal of Housing Economics, 20, 171-190.

Attanasio, O., Blow, L., Hamilton, R., Leicester, A. (2009). Booms and Busts: Consumption, House Prices and Expectations. Economica, 76, 20-50.

Bahaj, S. A., Foulis. A., Pinter, G. (2019). Home Values and Firm Behaviour, Discussion paper, Centre for Macroeconomics.

Bordo, M. D., Jeanne, O. (2002). Boom-Downturns in Asset Prices, Economic Instability and Monetary Policy. CEPR Discussion Paper No. 3398. 
Borio, C., Lowe, P. (2002). Asset Prices, Financial and Monetary Stability: Exploring the Nexus. BIS Working Papers 114.

Bostic, R., Gabriel, S., Painter, G. (2009). Housing Wealth, Financial Wealth, and Consumption: New Evidence from Micro Data. Regional Science and Urban Economics, 39, 79-89.

Bracke, P. (2013). How Long Do Housing Cycles Last? A Duration Analysis for 19 OECD Countries. Journal of Housing Economics, 213-230.

Bry, G., Boschan, C. (1971). Cyclical Analysis of Time Series: Selected Procedures and Computer Programs. NBER Technical Paper No. 20.

Byun, KJ., The U.S. Housing Bubble and Bust: Impacts on Employment, Monthly Labour Review, December 2010, 3-17.

Campbell, J., Cocco, J. (2007). Do house prices affect consumption? evidence from micro data. Journal of Monetary Economic, 54, 591-621.

Ceron, J., Suarez, J. (2006). Hot and Cold Housing Markets: International Evidence. CEPR Discussion Paper No. 5411.

Cesa-Bianchi, A. (2013). Housing Cycles and Macroeconomic Fluctuations: A Global Perspective. Journal of International Money and Finance, 37, 215-238.

Chaney, T., Sraer, D., Thesmar, D. (2012). The Collateral Channel: How Real Estate Shocks Affect Corporate Investment. American Economic Review, 102, 2381-2409.

Ciarlone, A. (2015). House Price Cycles in Emerging Economies. Studies in Economics and Finance.

Claessens, S, Kose, M.A., Terrones, M. E. (2011). Financial cycles: What? How? When?, IMF Working Paper WP/11/76.

Cunningham, R., Kolet, I. (2011). Housing Market Cycles and Duration Dependence. Journal of Applied Economics, 569 - 586.

Davies, M., Gyntelberg, J., Chan, J. (2008). Housing Finance Agencies in Asia, BIS Working Papers, No 241.

Demary M. (2010). The Interplay between Output, Inflation, Interest Rates and House Prices: International Evidence. Journal of Property Research, 27, 1-18.

Devpura, N., Narayan, P.K.(2020). Hourly OilPrice Volatility:The RoleofCOVID-19. Energy Research Letters, 1(2), 13683. https://doi.org/10.46557/001c.13683

Drought, S., Donald, C. (2011). Forecasting House Price Inflation: a Model Combination Approach, Reserve Bank of New Zealand, Discussion Paper DP2011/07.

Harding, D., Pagan, A. (2002). Dissecting the Cycle: A Methodological Investigation. Journal of Monetary Economics, 49, 365-381.

Harman, Y.S., Zuehlke, T.W. (2007). Nonlinear Duration Dependence in Stock Market Cycles. Review of Financial Economics, 16, 350-362.

Haroon, O., and Rizvi, S.A.R. (2020) Flatten the Curve and Stock Market LiquidityAn Inquiry into Emerging Economies, Emerging Markets Finance and Trade, 56, 2151-2161; https://doi.org/10.1080/1540496X.2020.1784716.

Iyke, B. N. (2018). Assessing the Effects of Housing Market Shocks on Output: the Case of South Africa. Studies in Economics and Finance, 35, 287-306.

Iyke, B. N. (2020a). COVID-19: The Reaction of US Oil and Gas Producers to the Pandemic. Energy Research Letters, 1(2), 13912. https://doi. org/10.46557/001c.13912

Kartashova, K., Tomlin, B. (2017). House Prices, Consumption and the Role of Non-Mortgage Debt. Journal of Banking and Finance, 83, 121-134. 
Lam, P. S. (2004). A Markov-Switching Model of GNP Growth with Duration Dependence. International Economic Review, 175-204.

Lunde, A., Allan, T. G. (2004). Duration Dependence in Stock Prices: an Analysis of Bull and Bear Markets. Journal of Business and Economic Statistics, 253-273.

Mian, A., Sufi, A. (2011). House Prices, Home Equity Based Borrowing, and the U.S. Household Leverage Crisis. American Economic Review, 101,2132-2156.

Mikhed, V. Zemcik, P. (2009). Do House Prices Reflect Fundamentals? Aggregate and Panel Data Evidence. Journal of Housing Economics, 18, 140-149.

Mishra, A.K., Rath, B.N., and Dash, A.K. (2020) Does the Indian Financial Market Nosedive Because of the COVID-19 Outbreak, in Comparison to After Demonetisation and the GST? Emerging Markets Finance and Trade, 56, 21622180; https://doi.org/10/1080/1540496X.2020.1785425.

Narayan, P. K. (2020). Oil Price News and COVID-19-Is There any Connection? Energy Research Letters, 1, 13176. https://doi.org/10.46557/001c.13176

Narayan, P. K., and Popp, S. (2010). A New Unit Root Test with Two Structural Breaks in Level and Slope at Unknown Time. Journal of Applied Statistics, 37, 1425-1438.

Narayan, P. K., and Popp, S. (2013). Size and Power Properties of Structural Break Unit Root Tests. Applied Economics, 45, 721-728.

Ohn, J., Taylor, L., Pagan, A. (2004). Testing for Duration Dependence in Economic Cycles. Econometrics Journal, 7 , 528-549.

Ozanne, L., Thibodeau, T. (1983). Explaining Metropolitan Housing Price Differences. Journal of Urban Economics, 13, 51-66.

Peek, J., Wilcox, J.A. (1991). The Measurement and Determinants of Single-Family House Prices. Real Estate Economics, 19, 353-382.

Phan, D.H.B., and Narayan, P.K. (2020) Country Responses and the Reaction of the Stock Market to COVID-19-a Preliminary Exposition. Emerging Markets Finance and Trade, 56, 2138-2150; https://doi.org/10.1080/1540496X.2020.1784719

Pischke, J.S. (2018). Wage Flexibility and Employment Fluctuations: Evidence from the Housing Sector. Economica, 85, 407-427.

Posedel, P., Vizek, M. (2009). House Price Determinants in Transition and EU-15 Countries. Postcommunist Economies, 21, 327-343.

Posedel, P., Vizek, M. (2011). Are House Prices Characterized by Threshold Effects? Evidence from Developed and Post-Transition Countries. Finance Uver, 61, 584-600.

Prabheesh, K.P., Padhan, R., Garg, B. (2020). COVID-19 and the Oil Price-Stock Market Nexus: Evidence from Net Oil-Importing Countries. Energy Research Letters, 1(2), 13745. https://doi.org/10.46557/001c.13745.

Syriopoulos, T.h. (2006). Risk and Return Implications from Investing in Emerging European Stock Markets. Journal of International Financial Markets, Institutions and Money, 16, 283-299.

C.T., V., and Prabheesh, K.P. (2020). Implications of COVID-19 Pandemic on the Global Trade Networks. Emerging Markets Finance and Trade, 56, 2408-2421 https://doi.org/10.1080/1540496X.2020.1785426

Wang, Z., and Zhang, Q. (2014). Fundamental Factors in the Housing Markets of China. Journal of Housing Economics, 25, 53-61. 
Warnock, V.C., and Warnock, F.E. (2008). Markets and Housing Finance. Journal of Housing Economics, 17, 239-251.

Zhu, Haibin. (2006). The Structure of Housing Finance Markets and House Prices in Asia. BIS Quarterly Review December, 55-70. 